\title{
O desenvolvimento profissional docente na contemporaneidade: implicações transformadoras para o ser e para o fazer
}

\author{
Teachers' professional development in contemporaneity: \\ transformative implications for being and doing
}
El desarrollo profesional docente en la contemporaneidad: implicaciones transformadoras para el ser y el hacer

\author{
BETTINA STEREN DOS SANTOS* \\ CARLA SPAGNOLO** \\ Claus DieTER STÖBAUS****
}

\begin{abstract}
RESUMO
Este estudo apresenta um diálogo teórico acerca do desenvolvimento profissional docente e de suas implicações para a aprendizagem dos professores em uma perspectiva integrada entre os binômios pessoa/profissional e teoria/ prática. Tem como objetivo refletir sobre os distintos aspectos que compõem o desenvolvimento profissional e sobre as possibilidades de transformação para a qualidade na formação contínua dos professores. Caracteriza-se como uma pesquisa bibliográfica, de cunho qualitativo, a partir das discussões entre os autores embasadas nas leituras dos distintos materiais. Conclui que a formação continuada de professores precisa ser repensada e desenvolvida levando em conta as bases que fundamentam as ações das instituições de ensino. O desenvolvimento profissional, por esse viés, assume papel importante na constituição de espaços que proporcionam a escuta ativa, o entendimento do outro e a percepção da complexidade enquanto compreensão do todo, a partir das necessidades individuais e coletivas.

Palavras-chave: Desenvolvimento profissional. Docência. Pessoa. Profissional.
\end{abstract}

\begin{abstract}
This study presents a theoretical dialogue about professional teacher development and its implications for teacher learning in an integrated perspective between the person/professional and theory/practice binomials. The objective was to reflect on the different aspects that make up the professional development and the possibilities of transformation for quality in the continuous education of teachers. The study is characterized as a qualitative bibliographical research, about the authors discussions based on the readings of the different materials. It was possible to understand that the continuous education of teachers needs to be rethought and be more developed taking into account the bases that support the actions of educational institutions. Professional development, through this bias, assumes an important role in the constitution of spaces that provide active listening, the understanding of the other and the perception of complexity as the comprehension of the whole, from individual and collective needs.
\end{abstract}

Keywords: Professional development. Teaching. Person. Professional.

\section{RESUMEN}

Este estudio presenta un diálogo teórico acerca del desarrollo profesional docente y sus implicaciones para el aprendizaje de los profesores en una perspectiva integrada entre los binomios persona/profesional y teoría/práctica. El objetivo fue reflexionar sobre los distintos aspectos que componen el desarrollo profesional y las posibilidades

\footnotetext{
* Professora titular na Pontifícia Universidade Católica do Rio Grande do Sul, atuando no Programa de Pós-graduação em Educação. Coordenadora do Grupo de Pesquisa Processos Motivacionais em Contextos Educativos. Coordenadora do Curso de Especialização em Psicopedagogia. Bolsista de Produtividade 1 em Pesquisa - PQ/CNPq. E-mail: bettina@pucrs.br

** Graduada em Licenciatura Plena em Educação Física. Mestre e doutora em Educação. Atualmente possui bolsa pelo Programa Nacional de Pós-doutorado PNPD/CAPES/MEC. Professora colaboradora do Programa de Pós-graduação em Educação da PUCRS, vinculada ao Centro de Estudos em Educação Superior (CEES).E-mail: carla.spagnolo@pucrs.br.

***Professor titular na Pontifícia Universidade Católica do Rio Grande do Sul, atuando nos Programas de Pós-graduação em Educação e de Gerontologia Biomédica. Possui graduação em Medicina, mestrado em Educação, doutorado em Ciências Humanas e Pós-doutorado em Psicologia.E-mail: Stobaus@ pucrs.br
} 
de transformación para la calidad en la formación continuada de los profesores. El estudio se caracteriza como una investigación bibliográfica, de cuño cualitativo, a partir de las discusiones entre los autores, basadas en las lecturas de los distintos materiales. Es posible comprender que la formación continuada de profesores necesita ser repensada y ser más desarrollada teniendo en cuenta las bases que fundamentan las acciones de las instituciones de enseñanza. El desarrollo profesional, por ese sesgo, desempeña un papel importante en la constitución de espacios que proporcionan la escucha activa, el entendimiento del otro y la percepción de la complejidad como la comprensión del todo, a partir de las necesidades individuales y colectivas.

Palabras clave: Desarrollo profesional. Docencia. Persona. Profesional.

\section{INTRODUÇÃO}

A docência é uma atividade profissional complexa pelas demandas cotidianas de saberes e por suas implicações na relação com o outro e na própria maneira de expressar e desenvolver os conhecimentos, em qualquer nível em que se atue, mormente se o assunto for educação superior. $\mathrm{O}$ papel do professor não se restringe unicamente a ensinar, mas ele precisa ter bem presente que deve constantemente oportunizar elementos que levem seus alunos a melhores aprendizagens. Utilizando para tal metodologias diferenciadas, através de questionamentos, levantamento de incertezas, utilização de problematizações, estudos de casos, entre outras. Seu labor abrange também orientações e mediações na busca de respostas e novas inquietações.

Do ponto de vista de seu desenvolvimento profissional, requer construir continuamente um maior sentido e relação entre sua vida pessoal e profissional, nos ambientes em que ele atua. Isso envolve o comprometimento com aprendizagens pessoais contínuas durante toda a sua carreira docente, para tentar superar as necessidades vigentes advindas do cotidiano em constante transformação (no qual está inserido como ser social). Implicando também o que lhe é proposto e exigido como docente, nas instituições educacionais, já que seus saberes e práticas estão relacionados não só às competências e às habilidades (que eles possuem ou necessitam desenvolver ao exercerem seu trabalho), mas às suas atitudes, histórias pessoais, experiências, enquanto pessoas e profissionais.

De fato, os resultados obtidos no decorrer da carreira profissional são frutos de suas próprias escolhas, oportunidades, conhecimentos, comprometimentos, transformações, pertencimentos, valorização profissional, dentro de determinado contexto sociopolítico, mas também da busca permanente de possibilidades que possam interferir e enriquecer qualitativamente suas próprias aprendizagens e seu fazer como docente.

Significa que o desenvolvimento profissional docente está intrinsecamente ligado à sua própria pessoa, impedindo alguma ruptura em dualidades que muitas vezes impedem práticas diferenciadas. Lembrando que concepções lineares e positivistas, como corpo/mente, teoria/prática, pessoal/profissional, ainda permeiam o contexto educacional e a percepção de muitos profissionais e podem inclusive ser deterministas de sua evolução (ou não) pessoal e profissional. Evidencia-se muitas vezes uma supremacia de conhecimentos práticos em detrimento dos saberes teóricos, ou vice-versa, conforme a área de especificidade, causando desconexão entre saberes.

Urge, por isso, (re)encontrar melhores espaços de interação entre as dimensões pessoais e profissionais, permitindo aos professores apropriar-se dos seus próprios processos de formação e (re)ssignificar sua profissionalidade docente.

O objetivo deste artigo é refletir sobre os distintos aspectos que compõem o desenvolvimento profissional, sem desconsiderar o pessoal, e sobre as possibilidades de transformação para a qualidade na formação continuada de professores, tanto em questões pessoais quanto profissionais. Caracteriza-se como uma pesquisa bibliográfica, a partir das discussões embasadas nas leituras e vivências dos autores, especialmente durante a realização do IV Seminário de Pessoa Adulta, Saúde e Educação, realizado em setembro de 2017. O tema central desse encontro, "A construção da profissionalidade docente: a pessoa em construção", promoveu espaços de socialização e discussões sobre a construção dos saberes docentes, desenvolvimento global do ser humano e outras questões educacionais contemporâneas que enfatizaram a importância do trabalho em redes colaborativas de conhecimento.

\section{REFERENCIAL TEÓRICO}

A formação profissional e pessoal do docente não se constrói por mera acumulação e realização de cursos, obtenção de mais conhecimentos ou entendimento de mais técnicas, mas também através de um trabalho de reflexão continuada e crítica sobre suas próprias práticas e de (re)construção permanente de sua identidade pessoal (NÓVOA, 1997). Por isso, é tão importante investir na 
própria pessoa em formação e dar um estatuto ao seu saber e experiências vivenciadas, muitas provenientes de seu fazer cotidiano, com reflexões construtivas pertinentes, significativas e positivas.

Percebe-se, para isso, a importância de espaços para discutir o tema desenvolvimento profissional em diferentes âmbitos. Todavia, algumas questões ainda são recorrentes, tendo em vista as limitações de ações transformadoras sobre o ser e sobre o fazer dos professores. Entre estas, podem estar: Como o desenvolvimento profissional pode contribuir para transformações no ser e fazer dos professores? O que é preciso para integralizar os distintos saberes necessários à profissionalidade docente?

Nessa conjuntura, discutir, refletir e pensar em ações diferenciadas para o desenvolvimento profissional docente consiste em um potente meio de transformação na maneira de perceber a construção da profissionalidade. $\mathrm{O}$ que exige um olhar mais amplo e expressivo para a formação pessoal e profissional, quer em colaboração, quer em movimentos de maior escuta, empatia ou ainda de problematização das necessidades desses professores.

Para Veiga (2012, p. 15), a formação assume uma posição de inacabamento, vinculada à história de vida dos sujeitos em contínuo processo de formação, que proporciona a preparação profissional. Como “[...] o processo de formação é multifacetado, plural, tem início e nunca tem fim". Nesse sentido, algumas constatações merecem atenção: teoria e prática não estão de maneira alguma dissociadas, pois são o ponto de partida e de chegada do processo de formação.

Esta deve ser compatível com determinado contexto sociopolítico e econômico, comprometida com perspectivas emancipatórias. Também implica preparar professores para momentos incertos, para mudanças. Significa articular a formação pessoal com a profissional, sendo uma forma de encontro e confronto com suas próprias experiências vivenciadas, pois se trata de um processo coletivo de construção docente, de reflexões em conjunto. Por fim, atitudes de colaboração e solidariedade são muito necessárias e pertinentes nesse contexto, através da descoberta do outro, do desenvolvimento do pensamento crítico e do processo reflexivo.

\section{O DESENVOLVIMENTO PROFISSIONAL: CONEXÕES ENTRE A FORMAÇÃO PESSOAL E PROFISSIONAL}

O conceito de desenvolvimento profissional está relacionado com uma visão mais ampla da aprendizagem profissional. Inclui a aprendizagem a partir da experiência, em grande parte desenvolvendo maior competência e aperfeiçoamento na atuação das práticas pedagógicas, as quais podem acontecer em diferentes tempos e contextos, em espaços formais, não formais e/ou informais.

A publicação da Unesco "Replantear la Educación" (2015) apresenta alguns pressupostos sobre o papel dos professores na contemporaneidade, com objetivos para a formação docente. Dentre os inúmeros aspectos apontados no documento em relação à formação docente, destacam-se a compreensão da diversidade, o olhar e o agir para a inclusão e o desenvolvimento de competências para (con)viver juntos. De acordo com a Unesco, os professores devem promover ambientes respeitosos e seguros em suas salas de aula, estimular a autoestima mais positiva e realista e a autonomia de seus aprendizes, além de eles mesmos continuarem a aprender e a evoluir profissionalmente. A formação pedagógica, nesse sentido, deve integrar a essência transdisciplinar e interdisciplinar, para que seja capaz de guiá-los a possibilidades de desenvolver a criatividade e ações compartilhadas para o bem do patrimônio natural e cultural.

A Lei de Diretrizes e Bases da Educação-LDB (BRASIL, 1996) é a legislação mais importante na educação brasileira. Em seus artigos 61 e 62, trata da formação de profissionais da educação, com a intenção de atender aos objetivos dos diferentes níveis e modalidades de ensino. Para isso, discorre sobre os principais fundamentos em dois aspectos: "1) associação entre teorias e práticas, inclusive mediante a capacitação em serviço; 2) aproveitamento da formação e experiências anteriores em instituições de ensino e outras atividades".

Embora os dois aspectos citados sejam de suma importância para balizar os parâmetros educacionais e, em consequência, direcionam para o desenvolvimento profissional docente, podem-se tecer algumas críticas em relação à terminologia utilizada, tais como capacitação e professor como facilitador.

A capacitação, citada pela LDB (BRASIL, 1996), pressupõe ações diretivas, em que os professores atuam como meros espectadores. Quanto a isso, sabese que o significado das aprendizagens dos professores, para melhorar a qualidade de sua docência, perpassa a transmissão de conhecimentos. O modelo de formação docente que se constituiu ao longo do tempo, enquanto momentos isolados e descontextualizados, já não atende às necessidades emergentes e atuais. Sendo assim, o processo de aprendizagem dos professores deve considerar seus conhecimentos prévios e suas vivências, já que sua formação deve incluir atividades práticas, encontros entre pares que promovam espaços de diálogos compartilhados sobre o ser professor.

Em debate sobre as políticas de formação continuada de professores, Gatti e Barreto (2009, p. 201) criticam o fracasso de muitas práticas, pois "os processos de formação continuada desenvolvidos desde os anos 
1980, quer para atualização ou complementação de conhecimentos, quer para preparar a implementação de uma reforma educativa, não produziram os efeitos esperados". Entre as várias razões para tais resultados, encontram-se: a dificuldade da formação em massa; a superficialidade dos cursos realizados; os limites dos recursos financeiros destinados; o problema para fornecer os instrumentos e o apoio necessários para a realização das mudanças esperadas; e, principalmente, a limitada e ausente participação dos professores na definição de políticas e diretrizes de formação docente, como categoria profissional, e na elaboração de projetos da escola de modo geral e da escola em que atuam.

As inquietações que emergem da palavra facilitador, adotada pelo documento da Unesco (2015), remetem ao papel do professor como facilitador da aprendizagem. Isto é, entende-se, nesse sentido, que o professor torna o processo mais fácil e simples. Tal percepção diverge da conduta de mediação, quer com o seu aluno, quer com pais e pares, a qual estimula aprendizagens significativas e desenvolvimento de competências por intermédio da problematização e da resolução de problemas.

Essa discussão é eminente, e alguns movimentos em direção às mudanças podem ser percebidos em nível mundial. Todavia ainda se está distante de práticas que efetivamente priorizem o desenvolvimento de saberes interdisciplinares, que tenham como ponto de partida a problematização da realidade, considerando a complexidade, a inteireza do ser (humano) e a busca contínua. Assim, a aprendizagem tem como principal premissa o modificar e ampliar conhecimentos, levando ao modo de agir e de ser.

Entende-se que os conceitos e as atividades referentes ao desenvolvimento profissional docente valorizam os distintos saberes, tempos e espaços. As aprendizagens dos professores, como parte de sua formação continuada, sem dúvida, passam pelas suas vivências, por sua experimentação/experienciação, pela inovação, pela transformação e pelas tentativas de novos modos de trabalho pedagógico.

Segundo Nóvoa (1997, p. 27), o desenvolvimento profissional é um processo de investigação diretamente articulado com as práticas educativas, e por esse viés, considera que as "[...] práticas de formação que tomam como referência as dimensões coletivas contribuem para a emancipação profissional e para a consolidação de uma profissão que é autônoma na produção de seus saberes e dos seus valores".

A constituição do saber docente é resultante da articulação dos três eixos (científico, pedagógico e empírico) e de seu caráter de provisoriedade e inacabamento (GRILLO e MATTEI, 2005). O eixo científico refere-se ao conhecimento construído no período de formação universitária e profissional. Já o eixo pedagógico é o que caracteriza a profissão do professor pelo estudo das Ciências da Educação. E o eixo empírico refere-se ao saber durante as experiências enquanto docente.

As autoras afirmam ainda que o saber docente é um saber plural, advindo também do processo de construção de identidade do professor, que resulta do cruzamento de duas dimensões: a social e a pessoal. A primeira se fundamenta no significado social da profissão num contexto específico e histórico; a segunda (o pessoal) está no sentido que cada professor confere à sua própria atividade docente, incluindo sua história de vida, valores, percepção de vida (GRILLO e MATTEI, 2005), bem como o sentimento de pertença e a motivação.

A motivação representa um dos fatores importantes para o aprendizado. Os motivos são forças que promovem a satisfação das necessidades humanas. O ponto de partida da motivação para aprender está no reconhecimento, por parte do estudante (e do docente), do significado daquilo que está aprendendo. Não se pode rigorosamente afirmar que são (apenas) os professores que motivam os estudantes a aprender, mas é notório que os mesmos têm (de ter e saber utilizar) subsídios didático-pedagógicos que podem contribuir expressivamente para a qualificação de práticas de sala de aula.

Tradicionalmente, há uma série de recomendações e alternativas que podem ser realizadas para favorecer a aprendizagem - sendo um dos fatores citados por Gil (2012) -, que são a variedade e as inovações nas metodologias utilizadas pelos docentes em suas aulas. A necessidade de romper paradigmas vem mobilizando as reflexões pedagógicas e indicando novas formas de organização dos currículos e de compreensão dos espaços de aprendizagem na sala de aula, alterações das relações teoria-prática, ensino-pesquisa-extensão, cultura-ciência, para nomear algumas dimensões fundamentais.

Para Enricone (2008), as mudanças e as inovações exigem dos professores uma constante (re)configuração de saberes e favorecem o reconhecimento da necessidade de trabalhar no sentido de transformar. Nesse sentido, cabe ressaltar que essas demandas são constatadas há muito tempo; no entanto, é evidente a dificuldade encontrada pelos professores para agirem em prol dessas transformações.

Por esse viés, à docência é uma atividade desafiadora, flexível e estratégica, pois exige saberes distintos e capacidade para enfrentar imprevistos. Para Jesus (2007), a diversidade de tarefas, a implementação de novos métodos, a pesquisa sobre os temas a ensinar, os novos desafios e o trabalho em colaboração com os colegas são aspectos fundamentais na profissão docente. A formação passa necessariamente pelo processo de (auto) 
aprendizagem e pelas relações que cada pessoa estabelece consigo mesma (intrapessoais) e com as outras pessoas (interpessoais).

Na percepção de Nóvoa (2007), formar é sempre formar-se (a si mesmo), e todo conhecimento é autoconhecimento; antes de ensinar, é preciso aprender. $\mathrm{O}$ professor nega seu papel quando tudo tem de ensinar e nada a aprender.

"Ensinar inexiste sem aprender", muito bem disse Freire (1998, p. 26). O trabalho docente é um processo de busca permanente, que exige criticidade e reflexividade. Tal exigência deve-se ao compromisso com a (sua própria) aprendizagem e com o desenvolvimento integral das pessoas com as quais o docente lida (seus alunos e seus pais, os seus pares).

A prática docente crítica envolve o movimento dinâmico e dialético entre o fazer e o pensar sobre o fazer. Freire (1998, p. 43-44) enfatizou sobre a importância da formação continuada para o ensinar enquanto prática crítico-reflexiva, afirmando que "[...] na formação permanente dos professores, o momento fundamental é o da reflexão crítica sobre a prática. É pensando criticamente a prática de hoje ou de ontem que se pode melhorar a próxima prática".

\section{CONTRIBUIÇÕES DA PSICOLOGIA POSITIVA PARA O DESENVOLVIMENTO PROFISSIONAL DOCENTE}

Estar imerso em um contexto de reflexão sobre si mesmo implica investimentos na formação continuada e na aprendizagem ao longo da vida, o que exige, de certa maneira, um olhar crítico e reflexivo sobre suas próprias experiências, sobre a relação com o outro e com saberes que advêm, segundo Nóvoa (1992), das técnicas, das distintas culturas, das artes, das tecnologias e de toda sua compreensão a respeito disso. Distante de ser novidade, mas verdadeiramente significativa e atual, a maneira como cada um ensina está diretamente interligada com aquilo que é como pessoa, especialmente quando exerce o ensino.

Diante disso, um dos fatores de relevância nas ações docentes é a 'busca de si' e do seu bem-estar como docente. Aspectos que podem favorecer o desenvolvimento profissional dos professores, mediante a busca da própria identidade e competências, que permeia por caminhos de formação continuada, consistente, ampla e ao mesmo tempo específica e peculiar.

A preocupação em relacionar os saberes docentes com o fazer pedagógico objetiva a integração entre o 'eu' profissional e o 'eu' pessoa, destaca Nóvoa (2007), afastando-se de toda fragmentação. As opções que cada um tem como professor perpassam a maneira de ser e a maneira de ensinar, havendo uma relação direta entre as duas. Acredita-se que a educação é um processo que envolve as relações interpessoais, que estão impregnadas pelos fenômenos emocionais e afetivos, além dos aspectos cognitivos.

Para Mosquera e Stobäus (2009, p. 49), a afetividade está organicamente vinculada ao processo de conhecimento, orientação e atuação do ser humano no meio social que o rodeia, e quanto mais tem conhecimento e melhor se conhece, mais sabe lidar consigo mesmo, com suas próprias emoções e sentimentos, com seu pensamento e manifestações. Para obter êxito, é imprescindível o desenvolvimento dos aspectos cognitivos em consonância com aspectos afetivos:

A conexão entre os sentimentos e o processo cognitivo propicia à pessoa uma vida de grande sensibilidade, que pode ser cada vez mais apreciada, na medida em que cabe a cada um de nós ir desenvolvendo suas capacidades afetivas e suas potencialidades, para tornar-nos realmente o que podemos e desejamos ser.

Parece significativo enfatizar a ideia de desenvolver potencialidades afetivas, pois, ao mesmo tempo em que propicia um conhecimento mais profundo do próprio ser, reflete, pela expressão dos sentimentos, as relações entre as pessoas, essenciais para a atividade vital. "O potencial afetivo do ser humano é o que capacita a conhecer as circunstâncias e os fatos do e no (seu) mundo", comentam Mosquera e Stobäus (2009, p. 51). Sendo assim, o conhecimento e o autoconhecimento são fundamentais para a convivência e relevantes para o processo educativo.

Nessas perspectivas, o professor, em primeiro lugar, precisa estar fortalecido como pessoa e ser um educador consciente e crítico. Aproveitar as formações para desenvolver capacidades e habilidades, tanto pessoal quanto profissionalmente, abrangendo aspectos cognitivos, afetivos e sociais. Afinal, ser professor é uma escolha que precisa de seriedade pelas inúmeras situações e atribuições que diariamente são incumbidas ao fazer e ser docente.

Emoções não devem ser compreendidas somente a partir da individualidade do professor, é indispensável distinguir o entorno profissional, social e cultural em que cada docente realiza seu trabalho. As relações emocionais dos professores, de acordo com Marchesi (2008), devem ter congruência com as vivências no trabalho com os colegas, influenciando as relações afetivas com os alunos, a interação com os pais, a adaptação às reformas na educação e a compreensão das próprias emoções.

Estas desempenham um papel determinante na satisfação profissional dos docentes, já que é fundamental preocupar-se com seu bem-estar. Portanto, indiscutivelmente, o bem-estar emocional é uma condição 
necessária para a boa prática educativa. "A fórmula" denota simplicidade: "É preciso sentir-se bem para educar bem [...]", destaca Marchesi (2008, p. 121), mas os fatores que se somam a esse estado de bem-estar são complexos e abrangentes, pois dependem de contextos pessoais e sociais.

A incessante busca pela adaptação, compreensão e desenvolvimento de competências emocionais do próprio professor e dos (seus) estudantes se traduz no bem-estar em sala de aula e na escola, lembrando dos subsídios na Psicologia Positiva, através do "florescimento", expressão utilizada por Seligman (2011) para destacar elementos de um estado de bem-estar.

O objetivo da Psicologia Positiva, segundo o autor, deriva da norma de aumentar a satisfação com a vida no planeta, mas complementa com uma nova compreensão sobre a natureza da felicidade e do bem-estar, com a própria teoria do bem-estar, dizendo que é um construto que, por sua vez, tem diversos elementos mensuráveis, os quais são enumerados da seguinte forma: “[...] emoção positiva, engajamento, sentido, relacionamentos positivos e realização" (SELIGMAN, 2011, p. 27).

Sobre emoção positiva, o autor (p. 36) explica que é uma variável subjetiva, definida por aquilo que é pensado e sentido, e conclui que "[...] o bem-estar não pode existir apenas na sua cabeça: ele é uma combinação de sentir-se bem e efetivamente ter sentido, bons relacionamentos e realização. O modo como escolhemos nossa trajetória de vida é maximizando todos esses cinco elementos [...]".

Nessa concepção, o objetivo da Psicologia Positiva sobre bem-estar é avaliar e produzir o florescimento humano, o qual é constituído dos cinco elementos já citados, além de autoestima, otimismo, resiliência e relacionamentos positivos.

Os professores, com o intuito de buscar a felicidade na função docente, podem permitir-se trilhar caminhos que proporcionem maior satisfação, competência e bemestar.

Seligman (2011, p. 262) argumenta que se podem fazer escolhas positivas e buscar o crescimento pessoal pelo florescimento:

Todos nós podemos dizer "sim" a mais emoção positiva. Todos nós podemos dizer "sim" a mais engajamento. Todos nós podemos dizer "sim" a melhores relacionamentos. Todos nós podemos dizer "sim" ao sentido na vida. Todos nós podemos dizer "sim" a uma realização mais positiva. Todos nós podemos dizer "sim" a mais bem-estar.

Isso significa que é possível constituir outro sentido para a vida pessoal e profissional, dependendo primordialmente das opções que cada pessoa faz no decorrer de sua vida. Muitas vezes, as pessoas se deparam com um paradoxo entre o dizer e o fazer. Sabe-se que a ação sempre é mais difícil que o discurso, pois requer força de vontade, determinação e reflexão sobre as próprias condutas.

A formação docente continuada, em diferentes aspectos, abre caminhos para novos saberes e fazeres. Pode ajudar a desenvolver mais aspectos de autoconfiança e ampliação de conhecimentos e ações transformadoras que podem resultar em maior valorização e credibilidade da comunidade escolar e da sociedade em geral. O (re)conhecimento do entorno social, os conhecimentos e práticas sobre motivação extrínseca e intrínseca, o desejo de querer e sonhar com melhores condições e com um mundo com mais cooperação e menos desigualdades, aumentam a perspectiva de vida e consequentemente o bem-estar, inclusive de docentes.

Marchesi (2008, p. 154) diz que a obtenção de uma relativa satisfação profissional na ação docente está relacionada principalmente à própria trajetória profissional e acadêmica e das condições laborais e profissionais em que realizam seu trabalho. O desenvolvimento de fatores protetores contribui para manter o ânimo e a dedicação à tarefa educativa, "a atualização das suas competências profissionais, o desenvolvimento de relações positivas com amigos-colegas, a participação em alguns projetos inovadores, o equilíbrio emocional e a busca do sentido da sua atividade".

Para Albert (2013), os docentes têm papel fundamental no processo de ensino. Dessa forma, é importante adaptar $a$ formação às suas necessidades concretas, priorizando o acompanhamento e o assessoramento em detrimento de ações formativas mais voltadas a elementos instrumentais e pedagógicas. Nesse sentido, para que os professores sejam capazes de inovar e mudar em direção a uma mais adequada docência na contemporaneidade, é importante levar em consideração os seguintes aspectos: partir de uma necessidade, seja por inquietudes, seja pela realidade em questão; possibilitar reflexões pedagógicas críticas e capacidade de construção e adaptação com protagonismo e colaboração, tanto curricular como de estratégias de desenvolvimento profissional e pessoal.

\section{NOVAS PERSPECTIVAS E DESAFIOS PARA A APRENDIZAGEM DOCENTE: PROTAGONISMO, COLABORAÇÃO E EMPATIA}

A formação continuada de professores precisa ser repensada e desenvolvida sobre as bases que fundamentam as ações das instituições de ensino, e isso é sinônimo de refletir sobre a própria prática, tanto em dimensões individuais quanto coletivas, no currículo, nos processos de aprendizagem, nas metodologias e na própria formação docente. 
Santos e Santos (2012) consideram que só é possível tecer saberes em processo de formação contínua nas múltiplas relações que transitam pelas práticas e são parte da vida profissional e pessoal do professor. Para isso, é necessário mobilizar as pessoas que fazem parte do processo educacional com mais protagonismo, com novas energias na criação de ambientes educativos inovadores e de espaços de aprendizagem que estejam à altura dos desafios da contemporaneidade.

Ao pensar sobre a formação continuada de professores para novas perspectivas, é indispensável enfatizar os processos de colaboração, os quais permitem às pessoas vivenciarem momentos distintos, em que a comunicação flui descentralizada, permitindo vez e voz aos envolvidos, e assim "a colaboração exige autonomia e não submissão; os sujeitos são pares, coautores nos diferentes processos de criação e (re)construção dos sentidos" (ALVES, 2012, p. 60).

A atividade colaborativa perpassa a existência de interação e intercâmbio de informações entre pessoas do grupo, na negociação e diálogo, na busca de consensos. Pressupõe alcançar objetivos pessoais e coletivos e interdependência não hierarquizada entre as pessoas (ESPINOSA, 2003). Exige, ainda, engajamento dialógico divergente e convergente para chegar a objetivos comuns.

Os conceitos sobre colaboração não são novos, no entanto sua aplicabilidade ainda demonstra-se fragilizada. O planejamento dos processos de ensino e de aprendizagem para os professores precisa considerar suas experiências cotidianas, prospectando espaços para realização de atividades colaborativas e aproximação entre colegas para melhor conhecer as diferentes realidades e práticas. Essas trocas podem resultar em aprendizagens significativas e resolução de questões e problemas reais.

Ressalta Alves (2012, p. 162):

Os espaços de formação docente podem constituir lócus ricos de aprendizados colaborativos, nos quais a liderança ocorre de forma situacional e diferentes estilos de aprendizagem afloram, permitindo que se aprenda com a diferença e a partir do outro - e, o mais importante, que se trabalhe junto, a favor de objetivos em comuns.

Para tanto, torna-se fundamental reconhecer o professor como sujeito aprendente, protagonista, que constrói saberes decorrentes da prática cotidiana, das situações-problema interligadas ao conhecimento teórico e às relações inter e intrapessoais. As atividades colaborativas, nesse âmbito, potencializam a qualidade das aprendizagens.

A ideia de colaboração pode ser compreendida pela teoria sócio-histórico-cultural de Vygotsky (1979, 1984, 1993), ao conceber a singularidade do ser humano, constituída a partir de sua pertença a grupos sociais, histó- ricos e culturais específicos. O ser humano não se desenvolve, não realiza aprendizagens, não ascende às funções psíquicas superiores, não forma a sua consciência e não se constitui como sujeito sem o outro. Por sua vez, o outro é considerado indispensável para o processo de diálogo e desenvolvimento das aprendizagens ao longo de toda a vida.

O trabalho colaborativo entre os professores pode proporcionar o intercâmbio de atividades e o compartilhamento de estratégias que possibilitam compreender e desenvolver ações pedagógicas mais enriquecedoras e criativas.

A colaboração caminha conjuntamente com o processo de empatia. Para que as pessoas (nesse caso, os professores, seus estudantes, a equipe diretiva e possivelmente até os pais) possam desenvolver um trabalho em conjunto, de modo a respeitar as diferenças e valorizar os processos de construção, com aceitação das divergências e convergências (também em um sentido de uma educação mais inclusiva), é essencial conhecer e entender melhor o outro. Inclusive, tentando colocar-se empaticamente em seu lugar. Isso demanda compreender as necessidades, dificuldades, a maneira de pensar e agir do outro. Existe, ainda e talvez em supremacia, o processo empático consigo mesmo. Saber sobre como o outro se sente, faz e procura ajuda a identificar suas próprias necessidades, anseios e aspirações, contribui para o autoconhecimento e, consequentemente, para perceber melhor o seu lugar no coletivo e a importância das ações individuais para o crescimento do grupo no trabalho colaborativo. Mas deve proporcionar elementos que levem ao colocar-se no lugar do outro, para melhor entendê-lo e auxiliá-lo, não apenas julgar e criticar.

O termo "empatia" pode compreender o modo como os professores se relacionam, compreendem e respeitam o outro, a capacidade que têm de entender o outro, de se colocar na posição do outro, o que não significa ser igual ao outro. Casasus (2009, p. 191) expressa sua visão sobre a empatia afirmando que, para incorporar os princípios de uma comunicação empática, primeiro é necessário compreender e observar como ocorre a comunicação. Compreender "algo" é importante, porque, se não se compreende, relaciona-se com esse algo sob a influência dos condicionamentos do passado:

Na empatia, o foco não está em mim e sim no outro. Na empatia, esvazio-me das minhas emoções e evito que elas interfiram. Na empatia, foco a atenção no outro; coloco toda a atenção no outro, sem reserva. $\mathrm{Na}$ empatia, eu estou em disposição de benevolência para com o outro. Quando queremos ser empáticos com a outra pessoa, em vez de escolher o que ocorre conosco, decidimos nos manter em contato com a outra pessoa. Deixo de me preocupar comigo e trato de me manter na escuta profunda do outro. 
A empatia é uma necessidade fundamental na vida dos seres humanos, pelas possibilidades de observação, escuta e compreensão do outro e com o outro. Esse movimento ocasiona reflexos importantes sobre a vida da própria pessoa que 'pratica' a empatia.

As ações colaborativas partem de um olhar empático, cujas implicações demandam um processo reflexivo individual dos professores que influencia as decisões do grupo. Nesse sentido, ser proativo e sensível em relação ao outro é fator determinante no processo transformador do espaço educacional.

$\mathrm{O}$ entendimento sobre o que é protagonismo neste estudo refere-se à participação efetiva dos professores no ambiente em que desempenham sua função docente, tanto na proposta política pedagógica quanto no projeto de ensino individual e coletivo. Integra o conceito de colaboração e empatia vinculado às reflexões e às ações sobre a realidade em que eles atuam, amparado por distintas dinâmicas que ampliam o repertório conceitual, procedimental e atitudinal.

A ação reflexiva implica atitudes ativas e cuidadosas daquilo que se acredita, envolvendo intuição e emoção. Para Zeichner (1993), os professores reflexivos perguntam-se constantemente por que estão fazendo o que fazem em sala de aula, expressam criticamente opiniões e escutam e aceitam quando as críticas referem-se a sua prática, entendendo que tal processo visa à melhoria para o contexto no qual está inserido. Por outro lado, os professores que não refletem sobre o seu ensino aceitam naturalmente a realidade cotidiana das suas escolas.

Embora as mudanças dependam de inúmeros aspectos e fatores pertencentes a um sistema educacional amplo e (des)estruturado, os professores podem contraporse à passividade (com atitudes de escuta, colaboração, engajamento e criatividade), mobilizando-se para direções alternativas em que possam ocupar o tempo para fortalecer as relações entre pares e instituição, com alunos e com seus pais, além dos distintos saberes, para a conquista de espaços que permitam resgatar mais a confiança nos outros e em si mesmos, para iniciativas que promovam a valorização profissional sem desconsiderar o pessoal.

\section{CONSIDERAÇõES FINAIS}

Os processos de transformação nos ambientes educacionais demandam o envolvimento efetivo dos professores. O desenvolvimento profissional assume papel importante na constituição de espaços que proporcionam a escuta ativa, o entendimento do outro e a percepção da complexidade enquanto compreensão do todo, a partir das necessidades individuais e coletivas.
A relevância de ter espaços dentro dos contextos educacionais que possam promover trocas entre os dirigentes e docentes entre si pode proporcionar discussões significativas que levem os profissionais a um processo de análise, reflexão e construção de planos de ação mais criativos, na busca de transformações que acompanhem as necessidades da contemporaneidade.

Por outro lado, o tempo investido para efetivar esses processos depende de vários fatores, entre eles a prioridade que a instituição e os docentes dedicam para repensar sobre suas práticas. $\mathrm{O}$ que pode interferir na qualidade das aprendizagens docentes e contemplar as trocas de experiências e diálogos, indicativos de resultados de um planejamento colaborativo direcionado para novas e possíveis ações, rumo às mudanças desejadas.

Por isso, a relevância dos grupos de pesquisa que dialogam entre si, nas universidades, nos encontros acadêmicos dos mais diversos e em outros contextos educativos. Nesse sentido, estimular a reflexão a partir de percepções interdisciplinares e integrais pode contribuir significativamente para promover uma educação de maior qualidade e equidade para o Brasil.

\section{REFERÊNCIAS}

ALBERT, Elisabet. H. En la senda de la escuela 2.0: de cómo invisibilizar las tecnologías a cómo construir propuestas educativas para el siglo XXI - un estudio de caso colaborativo para reflexionar sobre la educación contemporánea. 2013. Tese (Doctorado en Pedagogía) - Universidad de Barcelona, BarcelonaS, 2013.

ALVES, Lynn. Aprendizagem em rede e formação docente: trilhando caminhos para a autonomia, a colaboração e a cooperação. In: VEIGA, Ilma P. A.; D'ÀVILA, Cristina (Orgs.). Profissão docente: novos sentidos, novas perspectivas. Campinas: Papirus, 2012. p. 151-162.

BRASIL. Presidência da República. Lei no 9394/96, de 20 de dezembro de 1996. Estabelece as diretrizes e bases para a educação nacional. Diário Oficial da União. Brasília-DF, 23 dez. 1996. Disponível em: <http://legislacao.planalto.gov.br/ legislacao>. Acesso em: 30 mar. 2015.

CASASSUS, Juan. Fundamentos da educação emocional. Brasília-DF: Unesco/Liber Livro, 2009.

CUNHA, António C. Ser professor: bases de uma sistematização teórica. Braga, Portugal: Casa do Professor, 2008.

ENRICONE, Délcia (Org.). Ser professor. Porto Alegre: EDIPUCRS, 2008

ESPINOSA, Maria P. P. Aprendemos. Cooperando o colaborando? Las claves del método. In: SÁNCHEZ, Francisco M. (Org.). Redes de comunicación en la enseñanza: las nuevas perspectivas del trabajo corporativo. Barcelona: Paidós, 2003. p. 95-127.

FRANKL, Viktor E. Psicoterapia para todos: uma psicoterapia coletiva para contrapor-se à neurose coletiva. Petrópolis: Vozes, 1990. 
FREIRE, Paulo. Pedagogia da autonomia: saberes necessários à prática educativa. São Paulo: Paz e Terra, 1998.

GATTI, Bernardete A.; BARRETO, Elba S. de S. Professores do Brasil: impasses e desafios. Brasília-DF: Unesco, 2009.

GIL, Antonio C. Didática do ensino superior. São Paulo: Atlas, 2012.

GRILLO, Marlene; MATTEI, Patrícia. Saberes docentes, identidade profissional e docência. In: ENRICONE, Délcia; GRILLO, Marlene. Educação Superior: vivências de futuro. Porto Alegre: EDIPUCRS, 2005.

JESUS, Saul N. de. Professor sem stress. Porto Alegre: Mediação, 2007.

JESUS, Saul N. de. Psicologia da educação. Coimbra-PT: Quarteto, 2004.

LISTON, Daniel P.; ZEICHNER, Kenneth M. Formación del profesorado y condiciones sociales de la escolarización. Madrid: Ediciones Morata, 1993.

MOSQUERA, Juan J. M.; STOBÄUS, Claus D. Educação pela afetividade. In: ENRICONE, Délcia (Org.). Professor como aprendiz: saberes docentes. Porto Alegre: EDIPUCRS, 2009 .

NÓVOA, António. Os professores e sua formação. Lisboa: Dom Quixote, 1997.
SELIGMAN, Martin E. P. Florescer: uma nova compreensão sobre a natureza da felicidade e do bem-estar. Rio de Janeiro: Objetiva, 2011.

TARDIF, Maurice. Saberes docentes e formação profissional. Petrópolis: Vozes, 2013.

UNESCO. Organización de las Naciones Unidas para la Educación, la Ciencia y la Cultura. Replantear la Educación. Hacía un bien común mundial? Basileia, Suíça: Unesco, 2015.

VEIGA, Ilma P. A. Docência como atividade profissional. In: VEIGA, Ilma P. A.; D’ÁVILA, Cristina (Org.). Profissão docente: novos sentidos, novas perspectivas. Campinas: Papirus, 2012.

VYGOTSKY, Lev. Consciousness as a problem in the psychology of behavior. Soviet Psychology, v. 17, n. 4, p. 3-35, 1979. Disponível em: <http://www.tandfonline.com/doi/ abs/10.2753/RPO1061-040517043>. Acesso em: 29 dez. 2017.

VYGOTSKY, Lev. A formação social da mente. São Paulo: Martins Fontes, 1984

VYGOTSKY, Lev. Pensamento e linguagem. São Paulo: Martins Fontes, 1993.

ZEICHNER, Kenneth M. A formação reflexiva de professores: ideias e práticas. Lisboa: Educa, 1993.

Recebido em 17-01-2018.

Aprovado em 19-03-2018. 